\title{
Vulnerability assessment of churches under earthquake hazard
}

\author{
E. Paupério ${ }^{1}$, X. Romão ${ }^{2}$, A. Arêde ${ }^{2}$, A. Costa ${ }^{3}$ \\ ${ }^{1}$ Instituto da Construção, Faculdade de Engenharia da Universidade do Porto, Porto, Portugal \\ ${ }^{2}$ Departamento de Engenharia Civil, Faculdade de Engenharia da Universidade do Porto, Porto, Portugal \\ ${ }^{3}$ Universidade de Aveiro, Porto, Portugal
}

\begin{abstract}
The development of a framework for the quantification of the seismic vulnerability of churches is presented. Given the advantages of having different areas of expertise contributing for the assessment of vulnerability, the proposed framework involves a multidisciplinary approach for the definition of the vulnerability of churches. The general scope and the conceptual definition of the proposed framework are discussed and it is established that vulnerability assessment must be carried out with respect to three fundamental components: the building, the collections and the building surroundings. Implementation details of the framework are then presented for the specific case of church heritage under seismic hazard. The applicability of the vulnerability assessment approach is illustrated using real case scenarios.
\end{abstract}

\section{INTRODUCTION}

Time has demonstrated that the occurrence of disasters, either natural or resulting from other sources, is inevitable. Minimization of human losses is the first and foremost priority when developing disaster mitigation strategies. Nevertheless, efforts must also be made to preserve the tangible cultural heritage, such as the archaeological heritage, the historical built environment and the movable heritage. As disasters ultimately cause an irreversible loss of heritage, adequate preventive disaster risk management policies should be devised to protect cultural heritage. However, since destruction of irreplaceable cultural resources as a consequence of disasters continues to occur, it can be seen that awareness about the need to reduce risk is still low. Recent events continue to show a weak record of implementation of protective measures to control or limit damage to cultural heritage, and also show a lengthy recovery time after the disaster. Thus, both the high vulnerability of cultural heritage to disasters and the need to develop adequate tools to reduce this vulnerability are apparent.

The development of sustainable risk mitigation strategies to preserve tangible cultural heritage threatened by disasters must be based on adequate data quantifying the vulnerability. Since disastrous events can generally be seen to affect larger areas, an overall representation of the referred heritage vulnerability should be made available, for example, at the city level (Jigyasu et al., 2010). Such need calls for the development of an urban vulnerability matrix which consists of a geographical information system mapping the heritage vulnerability of a given area for a number of hazard sources. The purpose of the data represented by the urban vulnerability matrix is then seen to be twofold: 1) it can be the basis for developing preventive risk mitigation measures; 2 ) it can help defining salvage strategies and operations to minimize heritage losses after a disastrous event.

Although the fundamental concept behind the development of an urban vulnerability matrix is not new, its usefulness depends on the adequacy of the information that it features. Therefore, the present article focuses on the development of a framework specifically devised for cultural heritage. This framework allows the quantification of the vulnerability for different hazard sources in a format suitable to be used as a risk management tool. The framework, currently under development, proposes a multidisciplinary approach to assess heritage vulnerability in which different areas of expertise contribute to evaluate several vulnerability indicators which are then combined to establish a single vulnerability index. A discussion about the need for such type of vulnerability assessment approach is presented next, followed by the conceptual definition of the proposed framework. Implementation details of the framework are presented for the case of church heritage under seismic hazard and are illustrated by a real case scenario. 


\section{HAZARD SOURCES AND}

\section{VULNERABILITY ASSESSMENT IN}

\section{CULTURAL HERITAGE}

Effective risk management for cultural resources is a complex task, in many cases due to the inability to obtain adequate knowledge of the assets and to the difficulty of calculating the true cost of the loss and damage. This situation is particularly important when addressing the vulnerability of building contents such as art collections or other movable assets with a significant value and a large number of items that may have different levels of sensitivity to a given hazard. Several methods have been proposed over the years to address the vulnerability of this type of cultural heritage for different hazards, more specifically in the context of museum collections. The concepts behind most of these approaches involve the quantification of global measures such as the probability of occurrence of the hazard, the percentage of objects in the collection that might be affected or the expected loss of value to the collection (Ashley-Smith, 1999). Currently, the most recognized vulnerability assessment methodologies of this category are those proposed by Waller (1995) and Michalski (2007). These are more adequate to assess the vulnerability of cultural assets for a particular type of damage scenarios, namely those termed "deterministic" by Ashley-Smith (1999), i.e. that occur more frequently. The importance of such threats, which have a direct effect on the collection, is often found to depend mostly on the materials and on specific properties of the collection items. Hence, the expertise of conservators and collection caretakers is paramount to apply adequately these approaches.

Aside from the "deterministic" damage scenarios, the vulnerability of cultural assets must also be analysed for less certain events. Ashley-Smith (1999) refers to some of these damage scenarios as "catastrophic", i.e. those involving events with a low probability of occurrence that have severe consequences. In such cases, the adequate characterization of the building properties is often fundamental for a reliable vulnerability assessment. Hence, methods such as those in Waller (1995) and Michalski (2007) are inadequate since they do not include explicitly the influence of the construction characteristics and oversimplify the assessment. Therefore, construction and structural engineering expertise is a primary asset when dealing with such risk scenarios.

There are a number of methods for the assessment of building safety under different types of "probabilistic" hazards. From an engineering standpoint, these methods involve different degrees of refinement depending on the level of detail that is required, on the hazard under consideration and on the building typology under analysis. In general, these methods are divided into: 1) methods requiring extensive numerical simulation of the construction be- haviour, and 2) rapid safety assessment methods based on empirical vulnerability indicators that use data from in-situ surveys of the construction. Given its simplicity, the second type of methods is favoured for the proposed vulnerability assessment framework.

In addition to the collection and building characteristics, some factors related to the construction surroundings should also be considered to obtain a reliable description of the vulnerability (Jigyasu et al., 2010). For example, for earthquake risk, extensive damage or collapse of buildings surrounding the cultural heritage under analysis can block the access roads, as a result of which fire brigades and civil protection services may not be able to carry out rescue and safety assessment operations readily, (Jigyasu et al., 2010). Based on these arguments, the assessment of heritage vulnerability and the development of the urban vulnerability matrix for several hazard sources are seen to require the combination of three types of data inputs: 1) data about the building; 2) data about the collections; and 3) data about the building surroundings and access routes. These data inputs require the involvement of different areas of expertise (engineering, conservation, urbanism), thus emphasising the need for a multidisciplinary vulnerability assessment framework.

\section{DESCRIPTION OF THE VULNERABILITY ASSESSMENT FRAMEWORK}

\subsection{Scope and general concepts}

The proposed framework addresses the vulnerability assessment of tangible cultural heritage under "probabilistic" hazard sources. Cultural heritage includes movable and immovable tangible heritage according to the following:

- Movable heritage includes objects and collections such as paintings, sculptures, ceramics or books. From an engineering perspective these are considered to be building contents.

- Immovable heritage includes part or the totality of a building which has been designated heritage for historical, architectural, decorative, religious, or other reasons. Immovable heritage also includes other cultural assets attached to the building (non-structural architectural elements such as statues, tiles and mosaics or fresco paintings).

The vulnerability assessment of heritage buildings requires skilled human resources, time and money which are always limited. This can be especially problematic when there are many heritage buildings in a given area. Therefore, one of the objectives of the proposed framework is to define a vulnerability assessment methodology combining 
simplicity, efficiency and reliability, in order to optimize the available resources while producing useful data. Such optimization requires that basic data about the heritage construction has to be available for the assessment (e.g. architectural layouts as well as data about the structural system and the building materials).

\subsection{Conceptual description of the proposed vulnerability assessment framework}

To analyse the vulnerability for a given hazard, the proposed approach defines a vulnerability index $V_{I}$ involving the weighted contribution of three vulnerability components: the building $\left(V_{I, B}\right)$, the contents $\left(V_{I, C}\right)$ and the surroundings $\left(V_{I, S}\right)$. In this context, the vulnerability index $V_{I}$ represents the heritage's susceptibility to lose value (e.g. cultural, historical, religious, monetary). The vulnerability index $V_{I, B}$ represents the building's susceptibility to lose value due to damages resulting from the hazard. The vulnerability index $V_{I, C}$ represents the susceptibility of losing part of the collection's value. The vulnerability index $V_{I, S}$ represents the potential increase in the loss in value of the previous components. These indicators should be determined by professionals from the corresponding areas of expertise that should interact with each other to share expert knowledge, thus making the proposed vulnerability assessment a truly multidisciplinary analysis. Hence, the value of $V_{I, C}$ should be established by conservators and collection care takers, the value of $V_{I, B}$ should be defined by construction or structural engineers, and the value of $V_{I, S}$ should be set by emergency management officers. The vulnerability index $V_{I}$ is then obtained by

$V_{I}=\frac{w_{B} \times V_{I, B}+w_{C} \times V_{I, C}+w_{S} \times V_{I, S}}{w_{B}+w_{C}+w_{S}}$

where $w_{B}, w_{C}$ and $w_{S}$ are the weights of indicators $V_{I, B}, V_{I, C}$ and $V_{I, S}$, respectively. The weights $w_{B}$ and $w_{C}$ are defined in Table 1 while $w_{S}$ is considered to be the average of $w_{B}$ and $w_{C}$. In a case where the immovable heritage includes cultural assets attached to the building, the value of $w_{B}$ should be increased by one level according to the values in Table 1 .

By defining the vulnerability indicators $V_{I, B}, V_{I, C}$ or $V_{I, S}$ such as to have them ranging between 0 and 1 , where 0 represents a state of no vulnerability and 1 represents a state of maximum vulnerability, the index $V_{I}$ is then seen to range also from 0 to 1 , where 0 and 1 have the same meaning as before. If any one of the methods considered to define $V_{I, B}, V_{I, C}$ and $V_{I, S}$ can produce a vulnerability value above 1 , the corresponding indicator must be set to 1 . In order to include the vulnerability assessment in a risk management tool such as the referred urban vulnerability matrix, the value of index $V_{I}$ must be assigned to a vulnerability level according to a given vulnerability scale. Although other scales could be developed, Table 2 establishes a possible one. In addition to this scale assignment based on the value of $V_{I}$, the individual values of the indicators $V_{I, B}, V_{I, C}$ or $V_{I, S}$ must also influence the level of vulnerability that is assigned to a given heritage building. It is fairly reasonable to assume that an assessment scenario where the three vulnerability indicators $V_{I, B}, V_{I, C}$ and $V_{I, S}$ have values below 1 must be treated differently than a situation where at least one of the referred indicators has a value of 1 , even if the value of $V_{I}$ is the same for both scenarios. For example, considering a simple assessment scenario where $w_{B}=w_{C}=w_{S}$, the situation where the three values of $V_{I, B}, V_{I, C}$ and $V_{I, S}$ are 0.5 , which then yields a $V_{I}$ value of 0.5 , is different than the situation where $V_{I, B}, V_{I, C}$ and $V_{I, S}$ are $1,0.5$ and 0 , although $V_{I}$ is also 0.5 . To address this later situation, it is suggested that the vulnerability level of the heritage building should be increased to the following level whenever one of the vulnerability indicators $V_{I, B}, V_{I, C}$ or $V_{I, S}$ is 1 . Therefore, for the simple case previously referred, the vulnerability level of the first scenario is 3 while that of the second scenario should be increased to 4 .

Table 1. Definition of weights $w_{B}$ and $w_{C}$

\begin{tabular}{|c|c|}
\hline$w_{B}$ & $w_{C}$ \\
\hline $\begin{array}{l}\text { Building with no special value: } \\
w_{B}=0.2\end{array}$ & $\begin{array}{l}\text { Collection with no special } \\
\text { value: } w_{C}=0.2\end{array}$ \\
\hline $\begin{array}{l}\text { Building with architectural or } \\
\text { constructive features of value: } \\
0.3<w_{B} \leq 0.5\end{array}$ & $\begin{array}{l}\text { Collection with some reli- } \\
\text { gious or cultural value but } \\
\text { easily replaced: } \\
0.3<w_{C} \leq 0.5\end{array}$ \\
\hline $\begin{array}{l}\text { Building with value for the } \mathrm{Mu}- \\
\text { nicipality. Building with an im- } \\
\text { portant cultural value for a town: } \\
0.3<w_{C} \leq 0.5\end{array}$ & $\begin{array}{l}\text { Collection with significant } \\
\text { religious, cultural or histori- } \\
\text { cal value for a town: } \\
0.3<w_{C} \leq 0.5\end{array}$ \\
\hline $\begin{array}{l}\text { Building with value for the gen- } \\
\text { eral public. Building with an im- } \\
\text { portant cultural value: } \\
0.3<w_{C} \leq 0.5\end{array}$ & $\begin{array}{l}\text { Irreplaceable collection with } \\
\text { significant religious, cultural } \\
\text { or historical value: } \\
0.3<w_{C} \leq 0.5\end{array}$ \\
\hline $\begin{array}{l}\text { Building listed as a National } \\
\text { Monument. Building with na- } \\
\text { tionwide cultural value: } w_{B}=1.0\end{array}$ & $\begin{array}{l}\text { Priceless collection with na- } \\
\text { tionwide value: } w_{C}=1.0\end{array}$ \\
\hline
\end{tabular}

Table 2. Vulnerability scale

\begin{tabular}{|c|c|c|}
\hline Scale & $V_{I}$ range & Description \\
\hline 1 & $0.0 \leq V_{I} \leq 0.2$ & $\begin{array}{l}\text { Vulnerability is very small. The } \\
\text { hazardous event will have small } \\
\text { consequences. }\end{array}$ \\
\hline 2 & $0.2 \leq V_{I} \leq 0.4$ & $\begin{array}{l}\text { Vulnerability is small. The hazardous } \\
\text { event will have some consequences. }\end{array}$ \\
\hline 3 & $0.4 \leq V_{I} \leq 0.6$ & $\begin{array}{l}\text { Vulnerability is medium. A } \\
\text { significant part of the asset will be } \\
\text { lost if the hazardous event occurs. }\end{array}$ \\
\hline 4 & $0.6 \leq V_{I} \leq 0.8$ & $\begin{array}{l}\text { Vulnerability is high. Most of the } \\
\text { asset will be lost if the hazardous } \\
\text { event occurs. }\end{array}$ \\
\hline 5 & $0.8 \leq V_{I} \leq 1.0$ & $\begin{array}{l}\text { Vulnerability is very high. All of the } \\
\text { asset will be lost if the hazardous } \\
\text { event occurs. }\end{array}$ \\
\hline
\end{tabular}




\section{IMPLEMENTATION DETAILS OF THE PROPOSED VULNERABILITY ASSESSMENT FRAMEWORK}

To illustrate the proposed framework, implementation details are discussed in the following for the case of churches under seismic hazard. Specific methods are proposed for the quantification of the vulnerability indicators $V_{I, B}, V_{I, C}$ and $V_{I, S}$ based on existing methodologies (with minor adaptations in some cases). The proposed indicators are then quantified for a case-study application involving two neoclassical churches of the Pico Island, Azores, Portugal (figure 1).

Despite the formal nature of the architecture that characterizes the churches analyzed herein, their building materials and techniques are considered to fall within the conceptual principles of vernacular architecture. Such principles can easily be found throughout the building typologies of that region as can be seen from the typical Pico Island houses represented in figure 2 . In addition, the symbolic nature and importance of these churches for the local population must also be emphasized since they represent safety through divine protection.
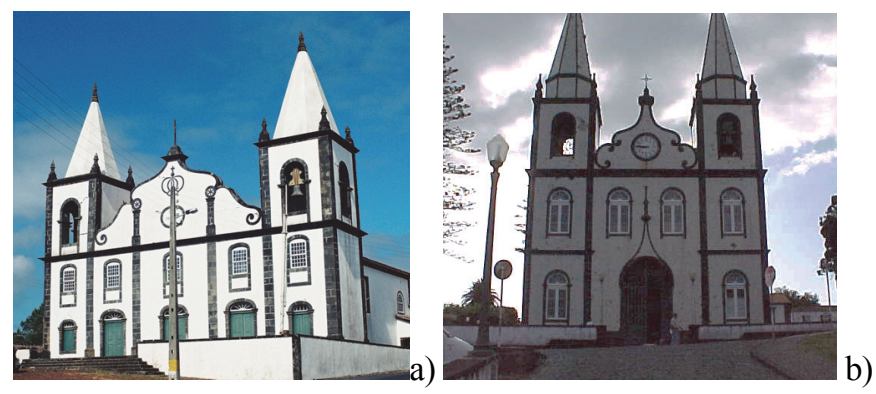

Figure 1. The Bandeiras (a) and the Madalena (b) churches. (Photo credits: Costa, A.).
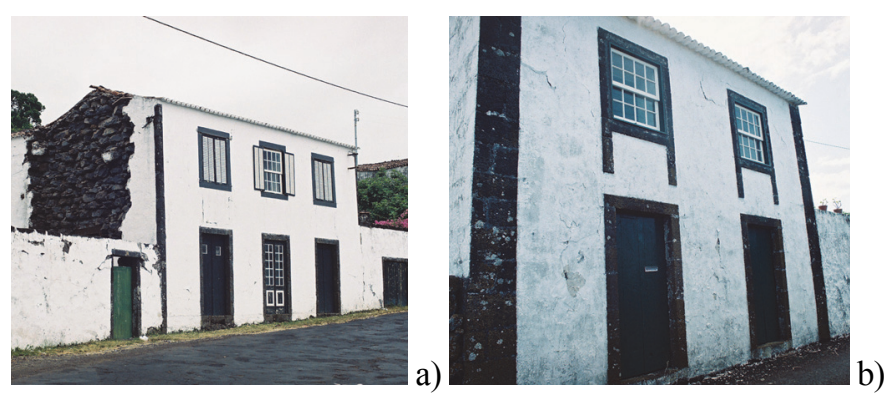

Figure 2. Typical houses of the Pico Island. (Photo credits: Costa, A.).

\subsection{Brief description of the churches analysed}

The churches under study are the two neoclassical buildings illustrated in figure figure Error! Reference source not found. The Bandeiras church (figure Error! Reference source not found.a) was built in 1860. The original Madalena church (figure Error! Reference source not found.b) was built in the fourteenth century. In the mid seventeenth century, this church was rebuilt and it was completed in 1891. The Bandeiras and Madalena churches have a similar typology and are made of three bodies that can be identified in figure 3: the first is the main entry, which includes the entrance lobby, the upper choir and the two lateral towers; the second is the main body with three longitudinal naves; finally, the third one includes the central altar, the lateral sacristies and the altar backside. The churches also have similar structural characteristics. The main structure is made of walls, arches resting on top of columns, and a roof which made of wood, such as the floor of the upper choir above the main entry. The exterior walls are made of two-leaf stone masonry, with a total thickness of $0.90 \mathrm{~m}$, and are the main structural elements. The tiles of the two-ways roof structure are laid on a liner supported by a wooden structure which, in turn, is supported by the exterior walls and interior longitudinal archways.
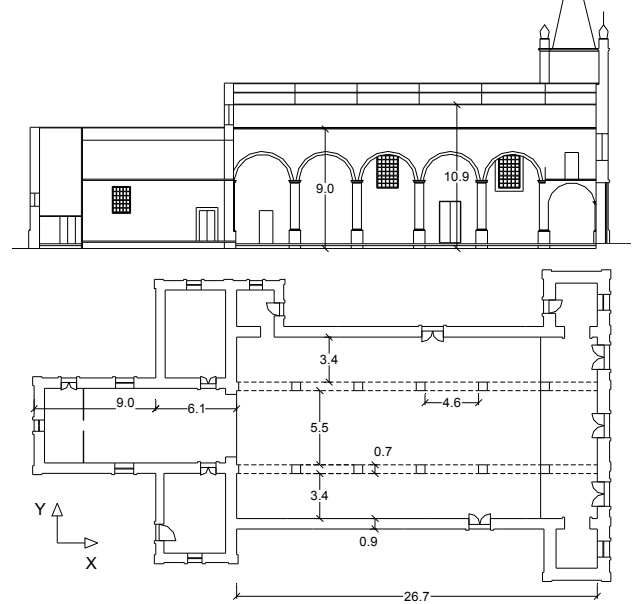

a)
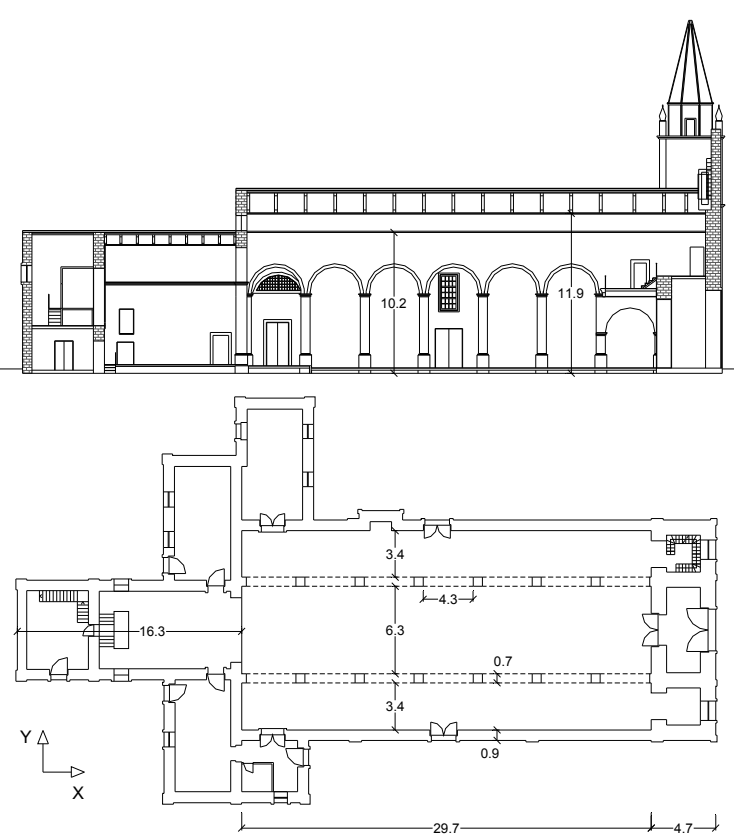

b)

Figure 3. Plan and longitudinal cross section views of the Bandeiras (a) and the Madalena (b) churches 


\subsection{Indicators for seismic vulnerability assessment}

\subsubsection{Description of the indicators}

Three procedures are presented in the following to determine the vulnerability indicators $V_{I, B}, V_{I, C}$ and $V_{I, S}$ for the seismic vulnerability assessment of churches. As previously referred, the selected procedures are not entirely original but instead make use of previously developed research on the matter.

For the case of the collection's vulnerability indicator $V_{I, C}$, a variant of the risk indicator presented by Waller (1995) is suggested. The proposed adaptation defines $V_{I, C}$ as

$$
V_{I, C}=F S \times L V
$$

where $F S$ is the fraction susceptible which represents part of the collection susceptible to a loss in value from exposure to a certain hazard (in this case an earthquake) and $L V$ is the maximum expected loss in value of $F S$. Both values are rates expressed as percentages. The surroundings' vulnerability indicator $V_{I, S}$ was developed using a format similar to that of the indicator proposed by Rodrigues (2009) to grade the fire risk of the streets of Porto, Portugal. The proposed expression defines $V_{I, S}$ as

$V_{I, S}=(A \times C-P) / 27$

where $A$ grades the level of accessibility of the heritage building location, $C$ grades the state of conservation of the buildings surrounding the heritage building, and $P$ grades the level of preparedness of the city emergency services to cope with the occurrence of an earthquake. To quantify $V_{I, S}$, the reference values of Table 3 are suggested for $A, C$ and $P$.

Table 3. Reference values for $A, C$ and $P$.

\begin{tabular}{lll}
\hline$A$ & $C$ & $P$ \\
\hline $3-$ Easy & $1-$ Good & $0-$ Low \\
6- Some difficulties & $2-$ Average & $1.5-$ Average \\
9- Difficult & $3-$ Bad & $3-$ Good \\
\hline
\end{tabular}

With respect to the quantification of $V_{I, B}$, the suggested vulnerability indicator is adapted from one of the indicators presented by Lourenço and Roque (2006) and is defined by

$$
V_{I, B}=\frac{\beta_{0} \times \sum_{i=1}^{m} A_{i} \times \gamma_{i} \times h_{i}}{\sum_{i=1}^{n} A_{i, d} \times\left(\operatorname{tg} \varphi \times \gamma_{i} \times h_{i}+f_{v k 0}\right)}
$$

where $\beta_{0}$ is an equivalent static seismic coefficient considered to be 0.22 (Lourenço and Roque, 2006), $\varphi$ is a friction angle considered to be $22^{\circ}$ (Lourenço and Roque, 2006), $f_{v k 0}$ is the cohesion of the wall material, $\gamma_{i}$ is the volumetric weight of the ith wall, $h_{i}$ is the height of the $i t h$ wall, $A_{i, d}$ is the in plan area of the ith earthquake resistant wall that is active when the earthquake effects are considered to occur in direction " $d$ ", and $n$ is the number of active walls when the earthquake effects are considered to occur in direction " $d$ ". With respect to the definition of direction " $d$ ", it is noted that the seismic vulnerability assessment of buildings is usually performed for two orthogonal plan directions to analyse the performance of the two main directions of the structural system. Therefore, considering the usual $\mathrm{X}$ and $\mathrm{Y}$ directions (e.g. see figure 3) two $V_{I, B}$ indicators are then obtained which are termed $V_{I, B, x}$ and $V_{I, B, y}$. The term $\sum A_{i} \times \gamma_{i} \times h_{i}$ represents the total weight of the $m$ earthquake resistant walls.

\subsubsection{Application to the selected churches}

For the quantification of $V_{I, C}, 90 \%$ of the contents of the Madalena church (i.e. everything except cloths and vestments) were considered to be vulnerable to seismic hazard $(F S=0.9)$. For the case of the Bandeiras church, $F S$ was considered to be 0.7 since its collection was found to be less susceptible. With respect to $L V$, given the high seismicity of the Azores, the earthquake effects and damages are expected to be high. Therefore, $L V$ was considered to be 0.70 for both churches. The value of $V_{I, C}$ was then found to be 0.49 for the Bandeiras church and 0.63 for the Madalena church. To quantify $V_{I, S}$, parameters $A, C$ and $P$ were considered to be the same for both churches and with values of 3 (easy access to the church), 2 (the surrounding buildings have an average state of conservation) and 1.5 (average level of preparedness), respectively. Hence, $V_{I, S}$ was found to be 0.17 for both churches.

With respect to $V_{I, B}$, as previously noted, it was analysed for the $\mathrm{X}$ and $\mathrm{Y}$ directions of the church indicated in figure 3, thus leading to indicators $V_{I, B, x}$ and $V_{I, B, y}$. Based on the authors' knowledge about the referred churches and on values proposed by the Italian Code (OPCM 3274, 2003), the cohesion of the walls $f_{v k 0}$ was estimated to be $35 \mathrm{kPa}$ for the Bandeiras church and $50 \mathrm{kPa}$ for the Madalena church, while their volumetric weight $\gamma$ was considered to be $18 \mathrm{kN} / \mathrm{m}^{3}$ (Arêde et al., 2012). Based on Eq. (3), indicators $V_{I, B, x}$ and $V_{I, B, y}$ were found to be 0.51 and 0.79 , respectively, for the Bandeiras church, and 0.43 and 0.66 , respectively, for the Madalena church. Given that $V_{I, B, x}$ and $V_{I, B, y}$ must be between 0 and 1 , it can be seen that, as expected, both churches are more vulnerable for the Y direction. Still the vulnerability values obtained for direction $\mathrm{X}$ are significant and should not be disregarded. Furthermore, according to the analysis of the damage of these two churches after the 1998 Azores earthquake presented by Azevedo and Guerreiro (2008), the values of $V_{I, B, x}$ and $V_{I, B, y}$ are seen to correlate well with those results which refer that the level of damage of the churches resulting from the earthquake required structural repair interventions before being able to reuse them. 
In order to obtain a value for the vulnerability in$\operatorname{dex} V_{I}$, values for the weights $w_{B}$ and $w_{C}$ must be defined according to Table 1. After analysing the characteristics of the churches and of their collections, the weights $w_{B}$ and $w_{C}$ were set as 0.5 and 0.6 for the Bandeiras church, and as 0.6 and 0.4 for the Madalena church. The value of $w_{B}$ for the Madalena church was initially found to be 0.4 but since this church possesses valuable cultural assets attached to the building, $w_{B}$ was increased to next level of Table 1. Since the indicator $V_{I, B, 1}$ was defined for two directions, yielding indicators $V_{I, B, x}$ and $V_{I, B, y}$, two vulnerability indexes $V_{I}, V_{I x}$ and $V_{I y}$, were also obtained for each church. However, the vulnerability of a given church must be characterized by a single value. Hence, only the higher of the two values is considered for each church. Therefore, for the Bandeiras church $V_{I x}$ and $V_{I y}$ were seen to be 0.39 and 0.47 , respectively, and for the Madalena church, they were seen to be 0.39 and 0.49 , respectively. The final $V_{I}$ values are then 0.47 for the Bandeiras church and 0.49 for the Madalena church.

Although methods such as the one proposed for the quantification of $V_{I, B}$ are simpler to apply, they are also expected to yield more conservative results. This level of conservatism reflects the simplified manner by which such approach accounts for the behaviour of the building structure under earthquake loading. For example, it can be seen that the proposed methodology only accounts for the walls that are expected to form the structural system of the church for each one of the main directions $\mathrm{X}$ and $\mathrm{Y}$, but does not account for other characteristics such as the level of connection between these walls or to other structural elements such as the floors and the roof. Despite the fact that for locations where the level of vulnerability is expected to be physically lower (e.g. in regions of lower seismic hazard) it is believed that such approaches are sufficient, for regions of higher seismic hazard more rigorous approaches should be utilized in a second stage of assessment. Finally, as previously referred, it can be seen that even for an adequate application of simple vulnerability assessment approaches, architectural layouts and basic knowledge about the characteristics of the building structure are required.

\section{FINAL COMMENTS}

Since disaster events cannot be prevented completely, adequate mechanisms must be developed to mitigate their effects. The consequences of recent disastrous events emphasize the need for adequate preventive disaster risk management measures incorporating the protection of cultural heritage. Hence, the advantages of having a framework to quantify the vulnerability of cultural heritage under disastrous hazard sources are evident.
The proposed vulnerability assessment framework presents two main advantages. First, it enables the quantification of vulnerability of a large number of cultural assets in a simple format suitable to be used in a valuable tool for risk management such as the urban vulnerability matrix (a geographical information system mapping the heritage vulnerability of a given area for several hazard sources). Second, by considering that vulnerability must be assessed with respect to three fundamental components (the building, the collections and the building surroundings), it proposes a multidisciplinary approach for the characterization of heritage vulnerability that involves inputs from different areas of expertise.

The general scope and the conceptual definition of the proposed framework, which is currently under development, were presented and implementation details were discussed for the seismic vulnerability assessment of church heritage. Real case scenarios were presented to illustrate the proposals.

\section{REFERENCES}

Ashley-Smith, J., 1999. Risk assessment for object conservation. Butterworth-Heinemann, Oxford.

Arêde, A., Costa, A., Moreira, D., Neves, N., 2012. Seismic analysis and strengthening of Pico Island Churches. Bulletin of Earthquake Engineering 10(1), 181-209.

Azevedo, J., Guerreiro, L., 2008. Damage in churches: a first evaluation. In Sismo 1998 - Açores. Uma década depois. Oliveira C.S., Costa, A., Nunes, J.C. (eds). (in Portuguese)

Jigyasu, R., King, J., Wijesuriya, G., 2010. Managing Disaster Risks for World Heritage. World Heritage Resource Manual. United Nations Educational, Scientific and Cultural Organization.

Lourenço, P., Roque, J., 2006. Simplified indexes for the seismic vulnerability of ancient masonry buildings. Construction and Building Materials 20(4), 200-208.

Michalski, S., 2007. ABC risk assessment scales for museum collections. ICCROM-CCI-ICN Reducing Risks to Collections Course, Sibiu, Romania.

OPCM 3274, 2003. Primi elementi in materia di criteri generali per la classificazione sismica del territorio nazionale e di normative tecniche per le costruzioni in zona sismica. Suppl. ord. n.72 alla G.U. n.105 del 8/5/2003 (in Italian).

Rodrigues, L., 2009. Fire safety in buildings of the historical city centre of Porto. MSc Thesis. Faculty of Engineering of the University of Porto, Porto (in Portuguese).

Waller, R., 1995. Risk Management Applied To Preventive Conservation. In: Storage of Natural History Collections: A Preventive Conservation Approach, Rose, C.L., Hawks, C.A., Genoways, H.H. (eds.). Society for the Preservation of Natural History Collections Iowa City. 